\section{Predictive Factors for Low Ankle Brachial Index in Patients with Systemic Lupus Erythematosus}

To the Editor:

The paper by Erdozain, et $a l^{1}$ described a cross-sectional study of 216 patients with systemic lupus erythematosus. Ankle brachial index (ABI) was used as a surrogate marker for peripheral arterial disease (PAD). The number of patients with $\mathrm{ABI}$ under 0.9 was $46(21.3 \%)$. In their multiple logistic regression analysis, age became a significant factor for low ABI. In contrast, cardiovascular risk factor, including diabetes mellitus, hypertension, hypercholesterolemia, or current smoking, did not become a significant variable. I have some concerns about this study.

First, the authors adopted low ABI as values lower than 0.9 , which has been widely accepted ${ }^{2}$. Although the authors handled 170 patients with normal $\mathrm{ABI}$ as a control group, there is a followup study that high $\mathrm{ABI}$ over 1.4 becomes a risk for cardiovascular disease (CVD) ${ }^{3}$. I suppose that the prevalence of high $\mathrm{ABI}$ is not frequently observed, and recommend presenting distribution of $\mathrm{ABI}$ values in their study.

Second, the authors verified 3 patients with symptomatic PAD, and there was no significant difference between low ABI group and normal ABI group in their Table 3. On this point, a false-positive for PAD by ABI should be handled with caution.

Finally, the authors selected a backward stepwise logistic regression analysis. This method includes all the related factors as independent variables to know the association with low ABI in the first step. Peduzzi, et $a l^{4}$ reported that the number of events per 1 independent variable should be 10 or higher to keep statistical power for logistic regression analysis. Although there is no gold standard to check the statistical validity, only 4 independent variables are permitted for their multivariate analysis. I recommend that the authors conduct further study with more patients with low ABI. This procedure would confirm the association between CVD risk factor and low ABI.

TOMOYUKI KAWADA, MD, PhD, Department of Hygiene and Public Health, Nippon Medical School, Tokyo, Japan. Address correspondence to Dr. T. Kawada, Department of Hygiene and Public Health, Nippon Medical School, 1-1-5 Sendagi, Bunkyo-Ku, Tokyo 113-8602, Japan.

E-mail: kawada@nms.ac.jp

\section{REFERENCES}

1. Erdozain JG, Villar I, Nieto J, Ruiz-Irastorza G. Peripheral arterial disease in systemic lupus erythematosus: prevalence and risk factors. J Rheumatol 2014;41:310-7.

2. Lin JS, Olson CM, Johnson ES, Whitlock EP. The ankle-brachial index for peripheral artery disease screening and cardiovascular disease prediction among asymptomatic adults: a systematic evidence review for the U.S. Preventive Services Task Force. Ann Intern Med 2013;159:333-41.

3. Rodondi N, Marques-Vidal P, Butler J, Sutton-Tyrrell K, Cornuz J, Satterfield S, et al. Markers of atherosclerosis and inflammation for prediction of coronary heart disease in older adults. Am J Epidemiol 2010;171:540-9.

4. Peduzzi P, Concato J, Kemper E, Holford TR, Feinstein AR. A simulation study of the number of events per variable in logistic regression analysis. J Clin Epidemiol 1996;49:1373-9.

J Rheumatol 2014;41:10; doi:10.3899/jrheum.140250 